\title{
Alterações imunológicas e antropométricas induzidas por uma ultramaratona em Kayak. Um estudo de caso
}

\author{
J. A. Rodrigues dos Santos ${ }^{1}$ \\ J. Candeias ${ }^{2}$ \\ M.C. Magalhães ${ }^{2}$
}

https://doi.org/10.5628/rpcd.06.02.143

\author{
${ }^{1}$ Universidade do Porto \\ Faculdade de Desporto \\ Portugal \\ ${ }^{2}$ Serviço de Imunologia \\ Hospital de S. João \\ Porto \\ Portugal
}

\section{RESUMO}

Replicando um estudo anterior com o mesmo canoísta veterano, foram analisados, no sangue periférico, os valores de várias células da função imune, bem como algumas medidas antropométricas, antes e um, cinco e dez dias após uma ultramaratona (UM) em Kayak. As amostras sanguíneas foram obtidas em jejum, às 9 horas da manhã e, pelo menos, mais de 12 horas após o último momento de esforço. Foram medidos o número de leucócitos e o número e percentagens de linfócitos, monócitos, neutrófilos, eosinófilos e basófilos. Por citometria de fluxo foram identificados as seguintes subséries linfocitárias (CD3+, $\mathrm{CD} 4+, \mathrm{CD} 8+, \mathrm{CD} 16+/ \mathrm{CD} 56+, \mathrm{CD} 19+)$, ratio $\mathrm{CD} 4+/ \mathrm{CD} 8+$, $\mathrm{CD} 3+\alpha \beta, \mathrm{CD} 3+\gamma \delta$, e os marcadores de activação (CD25+, CD94+ e HLA-DR), bem como as células "naive" (CD45RA+) e "memória" (CD45RO+). As alterações mais significativas após a UM incidiram na redução das células CD4+CD45RA+ (-14.8\%), CD94+ (-40\%), da ratio CD4+/CD8+ (-15.7\%) e no aumento das CD4+CD25+ (28\%), CD8+ (19\%),

CD8+CD25+ (36\%), CD25+ (29\%). Com excepção das células totais $\mathrm{CD} 25+$, cujos valores se mantiveram elevados, e das células NK, em que se acentuou a depressão pós-esforço ($13.6 \%$ ), ao $10^{\circ}$ dia após esforço todos os valores de partida foram recuperados e por vezes ultrapassados. Verificou-se uma redução significativa do peso corporal a expensas da redução da percentagem da massa gorda, o que indica um balanço energético negativo no decurso da UM. A evolução dos indicadores imunológicos, neste estudo, indicia uma boa capacidade adaptativa do sujeito a este tipo de esforços. As alterações provocadas pela UM parecem ter um carácter transitório e não se exprimiram por qualquer crise infecciosa das vias respiratórias superiores em todo o tempo do estudo.

Palavras-chave: ultramaratona, canoagem, sistema imune, CD4+, CD8+, CD16+/CD56+, CD19+, HLA-DR, CD25+, CD94+, CD45RA +, CD45RO+.

\begin{abstract}
Immunological and antropometric changes induced by an ultramarathon in kayak. A case study

This study, replicating a former study with the same master paddler, investigated the changes on the immune system, as well as some anthropometric indicators, before, and one, five, and ten days after an ultramarathon in kayak. The blood samples were collected in fasting state, at 9 a.m., at least 12 hours after the last exertion. The number of leukocytes and the number and percent of lymphocytes, monocytes, neutrophils, eosinophils, and basophils were assessed. By flow citometry, the following lymphocytes subsets were identified and assessed: $C D 3+, C D 4+, C D 8+, C D 16+/ C D 56+, C D 19+$, ratio $C D 4+/ C D 8+, C D 3+\alpha \beta, C D 3+\gamma \delta$, the activation markers $(C D 25+$, CD94+e HLA-DR), as well as the "naive" (CD45RA+) and "memo$r y$ " $(C D 45 R O+)$ cells. The most significant changes after the ultramarathon indicated the decrease of $C D 4+C D 45 R A+(-14.8 \%), C D 94+$ $(-40 \%), C D 4+/ C D 8+$ ratio $(-15.7 \%)$ and the increase of CD4+CD25+ (28\%), CD8 + (19\%), CD8+CD25+ (36\%),

CD25+ (29\%). Total CD25+ cells increase verified after exertion was sustained during the recovery period. The slight depression of the NK cells verified after the ultramarathon, was more pronounced (-13.6\%) at the $10^{\text {th }}$ day of recovery. The other cells, at the $10^{\text {th }}$ of recovery, returned or overpassed the basal values. A significant reduction of the body weight was verified supported by the concurrent reduction of the fat mass, what suggest a negative energetic balance during the ultramarathon. The evolution of the immunological indicators during the study indicated good adaptative capacity of the subject to this kind of exertion. The changes induced by the ultramarathon seem be transitory and didn't trigger any upper respiratory tract infection during the time of exertion or recovery days.
\end{abstract}

Key-Words: ultramarathon, canoeing, immune system, $C D 4+$, CD8+, CD16+/CD56+, CD19+, HLA-DR, CD25+, CD94+, CD45RA+, CD45RO+. 


\section{INTRODUÇÃO}

Em estudo anterior (40), com o mesmo atleta, verificamos uma marcada linfocitose, elevadas percentagens basais de linfócitos CD8+ e ratio CD4+/CD8+ abaixo de 1.0, quer em período de treino intenso quer após ultramaratona (UM), não se tendo verificado a ocorrência de qualquer episódio de infecção das vias respiratórias superiores. Alguns sinais indiciadores de imunodepressão não se exprimiram em qualquer processo infeccioso. A literatura aponta para o efeito protector do exercício físico moderado, enquanto o exercício físico intenso parece induzir debilidade imunológica que se pode manter expressa durante vários dias $(26,45)$ e que pode provocar o advento de processos de infecção do tracto respiratório superior (27). No entanto, mesmo o exercício físico de fraca intensidade mas muito prolongado, pode induzir alterações imunológicas que se mantêm durante vários dias (41). Reforçando a tese protectora foi verificado, em ultramaratonistas (29), que os mais experientes apresentavam o sistema imune adquirido mais potenciado, o que atenuava a emergência de episódios infecciosos das vias respiratórias superiores.

Em relação aos indicadores antropométricos, foi comprovado que esforços muito prolongados e de baixa intensidade mobilizam as reservas lipídicas, induzindo redução do peso corporal por diminuição da massa gorda (40).

Assim, o objectivo fundamental deste estudo foi replicar, com o mesmo atleta, o estudo anterior, tentando verificar se esforço idêntico em novas circunstâncias induziria idênticas alterações, quer ao nível do sistema imune quer ao nível antropométrico.

\section{MATERIAL E MÉTODOS}

\section{Sujeito}

Canoista veterano, com 56 anos de idade, praticante da modalidade há mais de 40 anos e com participação frequente em provas competitivas de longa duração.

\section{Percurso e condições particulares}

O percurso foi cumprido no rio Tejo desde Trillo (Espanha) até Lisboa (Portugal), durante 16 dias de esforço, descansando 1 dia em Aranjuez, 1 dia em Talavera la Reina e 1 dia em Vila Velha do Rodão. A quilometragem total rondou os $900 \mathrm{~km}$, que foram cumpridos em etapas que variaram entre os 50 e os $70 \mathrm{~km}$. O esforço mínimo diário a pagaiar nunca foi inferior a 6 horas. Várias etapas foram desenroladas debaixo de temperaturas superiores a 40 graus centígrados. As barragens foram todas ultrapassadas com o barco às costas, por vezes andando mais de $2 \mathrm{~km}$. Em dois momentos, por má provisão de alimentos, o sujeito esteve um dia sem se alimentar e com reduzido aporte hídrico.

\section{Composição corporal}

A determinação da composição corporal foi obtida a partir da mensuração das pregas de adiposidade subcutânea. A densidade corporal foi estimada a partir da equação de Durnin e Womersley (7) e a percentagem de gordura corporal a partir da equação de Siri (47).

\section{Amostras sanguíneas}

Amostras de sangue venoso periférico $(5 \mathrm{ml})$ foram recolhidas da veia antecubital em tubos contendo etilenodiaminotetracetato (EDTA) e analisadas dentro de 6 horas.

\section{Valores hematológicos}

Os leucócitos totais e uma contagem diferencial de cinco populações foi realizada usando os procedimentos padrão (Max M - Coulter Electronics ${ }^{\circledR}$ ).

\section{Anticorpos monoclonais}

Foram utilizados anticorpos monoclonais de ratinho dirigidos contra os antigénios da superfície celular dos leucócitos e conjugados com diferentes fluorocromos (FITC) e ficoeritrina (PERCEP CY5.5 e APC). O cluster, clone, fluorocromos, origem e especificidade e modo de associação desses anticorpos estão sumariados no quadro 1 . 
Quadro 1. Cluster, clone, corante fluorescente, fonte e especificidade dos anticorpos.

\begin{tabular}{|c|c|c|c|c|}
\hline Fluorescência & FITC & $\mathrm{PE}$ & PERCEP CY 5.5 & APC \\
\hline Monoclonal & CD45-(BD) & CD14-(BD) & & \\
\hline Clone & 201 & MфP9 & & \\
\hline Monoclonal & $\mathrm{CD} 3-(\mathrm{BD})$ & CD16+CD56- (BD) & CD45- (BD) & CD19-(BD) \\
\hline Clone & SK? & 3G8 MY31 & $2 \mathrm{D1}$ & SJ25C1 \\
\hline Monoclonal & $\mathrm{CD} 4-[\mathrm{BD}]$ & $\mathrm{CD} 8-(\mathrm{BD})$ & CD45- (BD) & $\mathrm{CD} 3-(\mathrm{BD})$ \\
\hline Clone & SK3 & SK1 & 201 & SK? \\
\hline Monoclonal & TRC A/B - (BD) & TCR G/D - (BD) & CD45- (BD) & $\mathrm{CD} 3-(\mathrm{BD})$ \\
\hline Clone & WT31 & $11 \mathrm{~F} 2$ & $2 D 1$ & SK? \\
\hline Monoclonal & $\mathrm{CD} 8-[\mathrm{BD}]$ & CD45RA - (PHARM.) & $\mathrm{CD} 45-(\mathrm{BD})$ & CD4- [COULTER] \\
\hline Clone & SK1 & HI100 & 201 & $13 B 8.2$ \\
\hline Monoclonal & $\mathrm{CD} 8-(\mathrm{BD})$ & CD45RO - (DAKO) & CD45- (BD) & CD4- (COULTER) \\
\hline Clone & SK1 & UCHL1 & $2 \mathrm{D1}$ & $13 B 8.2$ \\
\hline Monoclonal & CD94-(PHARM.) & CD56- (BD) & HLA DR - (BD) & CD45- (BD) \\
\hline Clone & HP3D9 & MY31 & L243 & 201 \\
\hline Monoclonal & CD11B - (COULTER) & $\mathrm{CD} 13-(\mathrm{BD})$ & CD45- (BD) & CD34- (BD) \\
\hline Clone & BEAR1 & L138 & $2 D 1$ & $8 \mathrm{G} 12$ \\
\hline Monoclonal & CD36 - (COULTER) & CD64 - (COULTER) & CD45- (BD) & CD14- (BD) \\
\hline Clone & FA6.152 & 22 & 201 & M $\varphi \mathrm{Pg}$ \\
\hline Monoclonal & $\mathrm{CD} 3-(\mathrm{BD})$ & HLA DR - (BD) & CD45- (BD) & $\mathrm{CD} 14-(\mathrm{BD})$ \\
\hline Clone & SK? & L243 & 201 & $\mathrm{M \varphi Pg}$ \\
\hline Monoclonal & $\mathrm{CD} 4-(\mathrm{BD})$ & CD25-(BD) & CD45- (BD) & $\mathrm{CD} 3-(\mathrm{BD})$ \\
\hline Clone & SK3 & $2 \mathrm{~A} 3$ & 201 & SK? \\
\hline Monoclonal & $\mathrm{CD} 8-(\mathrm{BD})$ & CD25- (BD) & CD45- (BD) & $\mathrm{CD} 3-(\mathrm{BD})$ \\
\hline Clone & SK1 & $2 A 3$ & 201 & SK? \\
\hline
\end{tabular}

BD - Becton Dickinson; PHARM. - Pharmingen; COULTER - Coulter Electronics

\section{Preparação das amostras para citometria de fluxo}

A determinação das subpopulações linfocitárias foi conseguida através de técnica de imunofluorescência directa. As amostras tratadas com EDTA foram incubadas ( $20 \mathrm{~min}, 4^{\circ} \mathrm{C}$, escuro) com $10 \mu \mathrm{l}$ de anticorpos monoclonais conjugados com FITC e $5 \mu$ PERCEP e APC. Depois os eritrócitos foram lisados durante 10 min. com $2 \mathrm{ml}$ de Facs Lysing Solution ${ }^{\circledR}(\mathrm{BD})$.

Finalmente as células foram lavadas em PBS, centrifugadas a $1500 \mathrm{r} / \mathrm{min}$. e resuspendidas em PBS. "List mode files" foram adquiridos num citómetro de fluxo (FACSCALIBUR, BD) dentro de 2 horas.

\section{Recolha de dados e análise}

A recolha de dados e análise foram realizados com o software de investigação FACSCALIBUR Lysis II 1.1. (BD), elaborando gráficos de pontos para a separa- ção dos linfócitos, usando janelas de dispersão frontal (FSC) versus janelas de dispersão lateral (SSC) e confirmados por "gate" em CD45 versus SSC, pelo menos nas células com mais alta intensidade de fluorescência em CD45. Foram analisados 10000 eventos. Foram usados 600 volts no multiplificador FL1 e 581 volts no FL2, uma amplificação linear para FL1 e uma compensação espectral para FL2. Para confirmar a população analisada, a percentagem de linfócitos obtida foi comparada com os diferentes valores das 5 subpopulações e com o resultado obtido com o primeiro gráfico de pontos - FL1 versus SSC - usando CD45/CD14 (Leucogate - BD). As células que mostraram uma dupla intensidade média de fluorescência, quando comparadas com o controle negativo, eram consideradas positivas. 


\section{RESULTADOS}

Antropometria

Quadro 2. Alterações antropométricas induzidas pela UM em kayak.

\begin{tabular}{|l|c|c|}
\hline Indicadores & Antes & 1 Dia Após \\
\hline Peso $(\mathrm{kg})$ & 85.3 & 82.5 \\
\hline Altura $[\mathrm{cm}$ ) & 188 & 188 \\
\hline Massa Gorda (\%) & 11.3 & 9.6 \\
\hline $\begin{array}{l}\text { Indice de Massa Corporal } \\
\text { (IMC) }\end{array}$ & 24.0 & 23.3 \\
\hline
\end{tabular}

Verificamos uma marcada redução do peso

e percentagem de gordura após a UM.

Quadro 4. Percentagens das subséries linfocitárias, antes e vários momentos após a realização da UM em kayak.

\begin{tabular}{|c|c|c|c|c|}
\hline Células & Antes & 1 Dia Após & 5 Dias Após & 10 Dias Após \\
\hline CD3+ & 71.3 & 71.3 & 71.5 & 71.5 \\
\hline $\mathrm{CD} 3+\mathrm{CD} 4+$ & 39.6 & 40.7 & 40.6 & 43.2 \\
\hline $\mathrm{CD} 3+\mathrm{CD} 8+$ & 28.0 & 27.9 & 27.5 & 21.0 \\
\hline CD3CD16+/CD56+ & 3.4 & 2.7 & 2.0 & 2.8 \\
\hline $\mathrm{CD} 3+\alpha \beta$ & 66.2 & 69.2 & 68.1 & 20.0 \\
\hline $\mathrm{CD} 3+\gamma \delta$ & 1.6 & 1.5 & 1.5 & 1.2 \\
\hline $\mathrm{CD} 3+\mathrm{DR}$ & 1.1 & 0.7 & 1.6 & 1.3 \\
\hline CD3CD25+ & 17.7 & 25.1 & 22.3 & 20.1 \\
\hline $\mathrm{CD} 4+$ & 39.6 & 40.7 & 40.6 & 43.2 \\
\hline CD4+CD45RA & 16.2 & 14.1 & 14.7 & 18.5 \\
\hline CD4+CD45R0 & 32.0 & 30.1 & 27.3 & 32.7 \\
\hline CD4+CD25 & 16.8 & 21.5 & 19.0 & 17.6 \\
\hline $\operatorname{CD} 8+$ & 29.9 & 35.6 & 33.8 & 27.6 \\
\hline CD8+CD45RA & 23.4 & 25.7 & 23.4 & 17.7 \\
\hline CD8+CD45R0 & 11.1 & 11.8 & 10.7 & 9.0 \\
\hline $\mathrm{CD} 8+\mathrm{CD} 25$ & 1.9 & 2.6 & 2.8 & 1.5 \\
\hline CD8+CD3- & 1.9 & 7.8 & 6.4 & 6.7 \\
\hline $\mathrm{CD} 16+/ \mathrm{CD} 56+$ & 22.0 & 20.4 & 18.7 & 19.0 \\
\hline $\mathrm{CD} 19+$ & 10.8 & 11.1 & 11.9 & 10.1 \\
\hline $\mathrm{CD} 25+$ & 23.4 & 30.2 & 29.1 & 30.2 \\
\hline CD56+ & 21.4 & 20.4 & 18.7 & 18.4 \\
\hline CD56+CD94+ & 12.5 & 10.1 & 9.1 & 10.9 \\
\hline CD56DR & 0.5 & 1.7 & 0.7 & 1.0 \\
\hline CD94+ & 17.3 & 12.3 & 11.4 & 12.5 \\
\hline CD94DR & 0.5 & 1.7 & 0.6 & 0.6 \\
\hline HLADR & 12.1 & 12.5 & 13.8 & 13.0 \\
\hline CD45RA & 63.1 & 60.3 & 61.1 & 59.2 \\
\hline CD45RO & 44.8 & 43.6 & 39.5 & 43.4 \\
\hline $\mathrm{CD} 4+/ \mathrm{CD} 8+$ & 1.32 & 1.14 & 1.20 & 1.56 \\
\hline
\end{tabular}


Quadro 3. Percentagem e número das células leucocitárias, antes e vários momentos após a realização da UM em kayak.

\begin{tabular}{|c|c|c|c|c|}
\hline Células & Antes & 1 Dia Após & 5 Dias Após & 10 Dias Após \\
\hline Leucócitos (X109/L] & 4.20 & 4.16 & 4.43 & 4.24 \\
\hline Linfócitos [\%] & 48.1 & 46.9 & 46.0 & 50.5 \\
\hline Linfócitos (X10\% $\left.10^{9}\right)$ & 2.02 & 1.95 & 2.04 & 2.14 \\
\hline Monócitos [\%] & 7.0 & 5.8 & 6.3 & 8.9 \\
\hline Monócitos (X109/L) & 0.3 & 0.2 & 0.3 & 0.4 \\
\hline Neutrófilos [\%] & 34.1 & 40.6 & 40.0 & 39.0 \\
\hline Granulócitos (X10 $10^{9} / \mathrm{L}$ ) & 1.4 & 1.7 & 1.8 & 1.7 \\
\hline Eosinófilos [\%] & 10.8 & 6.0 & 7.0 & 0.0 \\
\hline Eosinófilos (X109/L) & 0.5 & 0.2 & 0.3 & 0.0 \\
\hline Basófilos [\%] & 0.0 & 0.7 & 0.7 & 1.5 \\
\hline Basófilos (X10²/L) & 0.0 & 0.03 & 0.03 & 0.06 \\
\hline
\end{tabular}

\section{DISCUSSÃO}

O stresse físico induz alterações dos parâmetros imunológicos que estão, principalmente, dependentes do tipo de esforço (31) e do perfil de actividade física do sujeito (41). As alterações agudas do sistema imune induzidas por um esforço de endurance de curta duração desaparecem ao fim de poucas horas (35). Os esforços de endurance, regulares e muito prolongados, parecem produzir alterações com algum carácter crónico (40).

Foi comprovado (22), após exercício físico exaustivo e prolongado, um aumento do número de leucócitos que permaneceu elevado vários dias. Como adaptação crónica aos esforços de endurance parece acontecer uma redução do número basal de leucócitos (2), o que está de acordo com os valores relativamente baixos encontrados no sujeito do PE. A estabilidade verificada na contagem leucocitária indicia o carácter crónico desta adaptação e é corroborada pelo estudo anterior que realizamos com o mesmo atleta (40). Assim, os presentes dados conflituam, em parte, com a posição de Scharhag et al. (43) que afirmam que o exercício prolongado e moderado não altera de forma significativa a primeira linha de defesa imune. Esta discrepância pode radicar nas diferenças verificadas na situação experimental, já que o nosso raciocínio é reforçado pela verificação de elevadas percentagens basais de linfócitos e baixas de neutrófilos, ambas fora dos valores de referência laboratorial, e que pouco foram alteradas pela UM. O que indicia um estado crónico de debilidade imunológica que corrobora o nosso estudo anterior (40) e que pode radicar no perfil de esforço habitual deste atleta, o qual pode induzir um estado crónico de alteração da função linfocitária (28).

Será que o exercício prolongado constante altera de forma crónica a função imune? Será que a teoria da "open window", caracterizada pela diminuição das defesas imunes 1 a 9 horas após exercício prolongado, se pode estabelecer como défice crónico do sistema imunitário quando o treino de endurance muito prolongado se torna sistemático?

Estas perguntas são difíceis de responder já que, contrariando os nossos dados, foram encontrados, em maratonistas, valores de linfócitos ligeiramente inferiores aos normais (16), o que faz supor uma responsividade individual muito diferenciada aos estímulos de treino.

O elevado número de eosinófilos antes da UM pode significar, ou uma agressão parasitária, ou um episódio alérgico intenso. Vamos pela segunda hipótese, já que o canoísta deste estudo caracteriza-se por episódios recorrentes de rinite alérgica com manifestações de hipersensibilidade do Tipo I, com dificuldades respiratórias e prurido cutâneo generalizado, que podem ser detonados ou potenciados por choques anafiláticos de origem alimentar. A regressão a zero da contagem de eosinófilos ao $10^{\circ}$ dia de recuperação significa a eliminação do episódio alérgico ou agressão parasitária.

Parece que a resposta aguda ao esforço prolongado é o aumento do número de monócitos (1) que cai 
abaixo dos valores basais 3 horas após o exercício (14). No PE verificamos, 1 dia após a UM, uma redução quer na percentagem $(-17.2 \%)$ quer no número $(-33.3 \%)$ de monócitos o que, corroborando o estudo de Gabriel et al. (14), indicia uma mobilização dos monócitos para zonas de inflamação provocadas pelo exercício, evoluindo, assim, até macrófagos. Ao $10^{\circ}$ dia os valores de partida foram recuperados e mesmo ultrapassados o que pode significar a atenuação do processo fagocitário.

A percentagem total de linfócitos $\mathrm{T}(\mathrm{CD} 3+)$ aumenta após o esforço e rapidamente regressa aos valores basais (27), parecendo ser relativamente estável e independente do estado de treino $(20,35)$. Essa estabilidade foi verificada neste estudo.

As células $\mathrm{CD} 3+$ alfa/beta (a nível sistémico) e as CD3 + gama/delta (mais a nível do epitélio intestinal) apresentam um papel protectivo contra uma série de infecções $(5,24)$ e controlo do processo inflamatório (6) através da secreção de citocinas ou citotoxicidade. As CD3+alfa/beta aumentaram ligeiramente após a $\mathrm{UM}$, mantendo-se estável a percentagem das CD3 + gama/delta, indicando um bom estado de vigilância imunológica específico destas células. A inexistência de estudos em desporto com estas subséries linfocitárias não nos permite fazer comparações.

Os linfócitos $\mathrm{T}$ exprimindo os receptores para a interleucina-2 (CD25+) que segundo Baum et al. (3) não se modificam com o treino, sofreram após a UM um aumento significativo (29\%), o que indica uma superior activação e potenciação contra eventuais agressões de antigénios estranhos (36). Os linfócitos T reguladores $(\mathrm{CD} 4+\mathrm{CD} 25+)$, que correspondem a 5$10 \%$ das células CD4+ em animais normais (4), apresentavam valores de partida de $16.8 \%$ e subiram para $21.5 \%$ após a UM. Este aumento significativo (28\%) parece apontar para a potenciação da linha de defesa contra doenças infecciosas e auto-imunes. No período de recuperação verificou-se uma tendência para regresso aos valores de partida, o que pode significar que o repouso induz a redução do número de células reguladoras activadas por redução dos focos inflamatórios. Isto é confirmado pelo comportamento das células CD8+CD25+ que, após um pico ao $5^{\circ}$ dia de recuperação, regrediram para valores abaixo dos valores de partida ao $10^{\circ}$ dia, indiciando uma atenuação da função citotóxica/supressora.
Números baixos de linfócitos CD4+ estão relacionados com várias patologias e situações de imunodepressão. A percentagem de linfócitos $\mathrm{CD} 4+$ no decurso do estudo encontrou-se, sempre, dentro dos valores normais em atletas (10). Os valores destas células mantiveram-se praticamente inalterados após a UM, o que é corroborado por outros estudos (15, 32). No entanto, após esforço idêntico, foi verificada uma ligeira redução desta subsérie linfocitária (40). Ao $10^{\circ}$ dia e em relação aos valores pós-UM, verificámos um ligeiro aumento, quer da percentagem quer do número total de células $\mathrm{CD} 4+$ que passaram de $794 / \mu \mathrm{L}$ para $924 / \mu \mathrm{L}$ de sangue, ou seja, mais $16,3 \%$. Esta evolução dentro dos valores de normalidade (500 a 1600/ $\mathrm{LL}$ ) indica uma certa potenciação do sistema imune que estava ligeiramente debilitado no decurso do esforço, o que é parcialmente corroborado por outro trabalho (25), já que o protocolo experimental no nosso estudo foi muito mais agressivo. Os linfócitos T citotóxicos-supressores (CD8+) aumentaram $19 \%$ após a UM regredindo, ao $10^{\circ}$ dia, para valores inferiores aos de partida. Embora alguns autores, imediatamente após esforços prolongados, encontrem aumentos (12) ou reduções (32), quernos parecer que os esforços diários prolongados deste estudo podem ter induzido alterações bi-fásicas, com redução durante o esforço e com aumento após algumas horas de recuperação. Estas alterações coincidem com o comportamento da ratio CD4+/CD8+ que diminuiu $15.7 \%$ após a UM, aumentando depois. Estes dados corroboram o nosso estudo com o mesmo atleta (40) em que se verificou uma ratio basal de 0.87 em período de treino intenso e de 0.92 após UM, com recuperação posterior. Embora alguns autores tenham constatado que o treino moderado de endurance não altera esta ratio (46), a descida verificada neste estudo prendese, no nosso entender, com a elevada quilometragem desenvolvida diariamente. A redução temporária da ratio $\mathrm{CD} 4+/ \mathrm{CD} 8+$ pode significar o aumento da função citotóxica e um aumento da susceptibilidade a infecções (23). Os nossos dados não apontam para aí já que, quer durante o esforço quer nos 10 dias de recuperação, não se verificou nenhum episódio de infecção das vias respiratórias superiores, o que corrobora a experiência anterior do mesmo atleta em que a redução da ratio foi mais acentuada (40). 
Quer-nos parecer que durante um esforço exaustivo e prolongado e nos primeiros dias de recuperação, mesmo que alguns indicadores indiciem imunodepressão, o organismo apresenta-se em estado de alerta potenciado contra agressões externas, o que tende a desvalorizar o significado clínico das descidas temporárias da ratio $\mathrm{CD} 4+/ \mathrm{CD} 8+. \mathrm{O}$ aumento de $18.2 \%$ da ratio $\mathrm{CD} 4+/ \mathrm{CD} 8+$ ao $10^{\circ}$ dia é um sinal de aumento do potencial imunológico com o dominante aumento e influência dos linfócitos Tauxiliadores.

O exercício de endurance, intenso e exaustivo, promove a mobilização das células "natural killer" $(\mathrm{CD} 16+/ \mathrm{CD} 56+)$, que aumentam no sangue imediatamente após o esforço e, posteriormente, se deslocam para os focos de lesão ou inflamação (13). Também se verificou, após exercício de 1 hora a $75 \%$ do $\mathrm{VO}_{2} \mathrm{max}$, um aumento para o dobro das células $\mathrm{NK}$, que regressaram aos valores de partida dentro de 2 horas (35). O valor basal do sujeito do PE excede ligeiramente o valor superior de referência para atletas (10). O treino sistemático aumenta a contagem basal das células CD16+CD56+ (46), mas parece que tem de ser intenso e prolongado para induzir uma elevação crónica desta subsérie linfocitária (50), o que está de acordo com o perfil de treino deste sujeito. Após a UM verificamos uma redução de $7,3 \%$ das células NK que se acentuou (15\%) ao $3^{\circ}$ dia de recuperação. É de aceitar a hipótese que em esforços excepcionalmente prolongados, como no PE, aconteça uma deslocação das células NK durante o esforço para os locais de inflamação, induzindo reduções pronunciadas que se prolongam no tempo e que parecem depender das prostaglandinas libertadas pelos monócitos e neutrófilos activados (35). Esta asserção é corroborada por Shek et al. (44) que verificaram uma redução significativa das células NK 7 dias após exercício prolongado.

Também Baj et al. (2), em relação ao grupo controlo, verificaram, em ciclistas, uma contagem diminuída das células CD16+. Contrariando os nossos dados, comparando maratonistas com sedentários, verificaram-se idênticas contagens das células NK, mas superior actividade citotóxica naqueles (33). O cluster de diferenciação CD94+ designa células NK maduras e controla a sua função. Após exercício curto e intenso, células NK expressando CD94+ não se alteraram (18) e demonstram grande estabilidade mesmo em sujeitos altamente treinados (39). Tomando como referência os valores totais deste marcador, verificou-se uma redução de $40 \%$ após a UM que se acentuou ao $3^{\circ}$ dia. Esta redução é similar às verificadas em algumas patologias (17) e indicia a atenuação da função citotóxica das células NK. No entanto, ao contrário das situações patológicas instaladas, ao $10^{\circ}$ dia denota-se uma tendência para recuperar os valores de partida. Após a UM, a percentagem das células NK exprimindo CD94+ diminuiu, embora a percentagem de células activadas (CD94+DR) tenha aumentado $340 \%$, o que indicia aumento do potencial citotóxico das células NK. Os linfócitos B (CD19+) que sofrem aumentos marcantes após exercício regressam rapidamente aos valores de partida (8). No decurso do PE, a percentagem de linfócitos B (CD19+) não sofreu alterações significativas, o que é corroborado por outros estudos $(40,48)$. No entanto, contrariando os nossos dados, verificou-se que o treino reduz os valores basais das CD19+ (46). Os nossos resultados reforçam a posição de Pedersen (35) que afirma a grande estabilidade das células CD19+ e a impossibilidade de discernir a situação de treinado de não treinado a partir deste indicador.

A HLA-DR é uma glicoproteína presente na superfície de todas as células $\mathrm{B}$, monócitos e células $\mathrm{T}$ activadas. Está presente entre 11 a 18\% dos linfócitos normais periféricos. No PE as células exprimindo HLA-DR sofreram ligeiras variações entre os vários momentos de avaliação, demonstrando grande estabilidade que parece não ser afectada mesmo durante as adaptações agudas ao exercício $(12,20)$.

No PE, o valor basal das células CD4+CD45RA+ (16.2\%) é superior ao verificado em estudo anterior com o mesmo atleta $(9.9 \%)$, mas inferior ao verificado em futebolistas (38). Quer-nos parecer que o stresse recorrente determinado por cargas muito prolongadas fez diminuir a percentagem das células "naive" CD4+, que reduziram $14.8 \%$ após a UM, recuperando e ultrapassando os valores basais ao $10^{\circ}$ dia. Se o esforço for sistemático e recorrente parece haver uma tendência, no decurso do tempo, para a redução desta subsérie linfocitária (38). As células "memória" CD4+CD45RO+, que diminuiram ligeiramente após a UM, recuperaram os valores de partida ao $10^{\circ}$ dia, o que conflitua com o estudo de Woods et al. (49). 
As células CD8+CD45RA+, contrariamente ao verificado noutro estudo (50), sofreram um ligeiro aumento após a UM reduzindo quase $15 \%$ ao $10^{\circ}$ dia. As células $\mathrm{CD} 8+\mathrm{CD} 45 \mathrm{RO}+$ não se alteraram após a UM mas reduziram ao $10^{\circ}$ dia, o que conflitua com outro estudo (11). Esforços muito prolongados parecem apontar para a depressão das células memória CD8+.

As percentagens totais das células CD45RA $+\mathrm{e}$ $\mathrm{CD} 45 \mathrm{RO}+$ sofreram uma ligeira redução após a UM com comportamentos diferentes ao $3^{\circ}$ dia. Enquanto as células "naive" aumentavam ligeiramente, as "memória" acentuavam a redução (quase $12 \%$ em relação aos valores de partida). Ao $10^{\circ}$ dia reverteuse a situação diminuindo as CD45RA+ e recuperando os valores de partida as CD45RO+. Estes dados estão de acordo com Gabriel et al. (11) que afirmam que o exercício de endurance muito prolongado pode induzir a conversão dos linfócitos CD45RA + em $\mathrm{CD} 45 \mathrm{RO}+$, o que indica um superior estádio de activação e, talvez, uma superior maturação destas células. A regularidade da ratio CD45RA+/CD45RO+, verificada no PE, não justifica essa asserção. O comportamento individual das células "naive e "memória" das subséries CD4+ e CD8+ não nos permite ser muito conclusivos e abre espaço para novos trabalhos.

As células $\mathrm{T}$ reguladoras (CD4+CD25+), que parecem desempenhar um papel central na imunomodelação, previnem a autoimunidade, evitam a rejeição de enxertos, controlam as respostas à infecção e inibem os processos inflamatórios (19). Estas células reguladoras são antigénio-específicas e desempenham um papel primordial na imunidade adquirida. Aumentaram $28 \%$ após a UM, regredindo ao $10^{\circ}$ dia aos valores de partida. Contrariando os nossos dados, alguns autores $(3,21)$ afirmam que o treino não altera a percentagem deste tipo de células. Pensamos que as condições protocolares justificam as diferenças.

As células CD8+CD25+ aumentaram 36\% após esforço e recuperaram para os valores de partida ao $10^{\circ}$ dia. Pizza et al. (37) afirmam que quanto mais agressivo for o exercício maior é a expressão de activação dos linfócitos T citotóxicos-supressores. Parece que o treino aumenta os linfócitos
CD8 + CD25 + como resposta a uma dada carga (9). Os nossos dados confirmam que, embora o esforço tenha sido de intensidade fraca a moderada, devido ao elevado volume diário constituiu-se num significativo stressor do sistema imune.

Embora, os marcadores CD25+ específicos das $\mathrm{CD} 4+\mathrm{e} \mathrm{CD} 8+$ tenham regredido aos valores basais no $10^{\circ}$ dia, a percentagem total de células exprimindo receptores alfa para a IL-2 (CD25+) subiu 29\% após esforço, o que é corroborado pelo estudo de Mertens et al. (30), e continuou elevada ao $10^{\circ}$ dia, o que indicia a activação de outras células leucocitárias. Como em situação de infecção se verifica o aumento dos marcadores de activação linfocitária (e.g. CD25+), quer-nos parecer que os valores elevados ao $10^{\circ}$ dia podem indiciar uma situação de alguma disfunção imunológica. Esta especulação pode ser abusiva já que outros indicadores de activação (e.g. HLA-DR) não sofreram variações significativas no decurso do estudo, o que nos permite especular que a manutenção elevada dos valores das células exprimindo CD25 + representa um superior estado de imuno-vigilânica potenciado pela UM.

Verificou-se uma redução significativa de peso corporal, fundamentalmente à custa da massa gorda. Embora a redução de peso esteja relacionada com a diminuição da proliferação linfocitária estimulada por mitogénios, parece não afectar a imunidade inata do compartimento sanguíneo (34). Shore et al. (46) afirmam que quando o volume de treino é suficiente para induzir um balanço energético negativo, como aconteceu no PE, o sistema imune pode ser negativamente afectado. Quer-nos parecer que a boa condição física do sujeito e a grande adaptabilidade a este tipo de esforços obstou a disfunções marcantes do sistema imune.

Podemos concluir que, seja pelo carácter protector da experiência anterior (40), seja pelo habitual perfil de actividade deste atleta, no PE, embora levado a efeito em situações climatéricas e nutricionais muito agressivas, verificaram-se ligeiras alterações do sistema imune, o que evidencia a óptima capacidade adaptativa deste atleta a este tipo de esforços. Embora algumas alterações persistam ao $10^{\circ}$ dia de recuperação, pensamos que são transitórias e não indiciadoras de imunodepressão. 


\section{CORRESPONDÊNCIA}

José Augusto Rodrigues dos Santos

Faculdade de Desporto

Universidade do Porto

Rua Dr. Plácido Costa, 91

4200-450 Porto

Portugal

jaugusto@fcdef.up.pt

\section{BIBLIOGRAFIA}

1. Bain, BJ; Phillips, D; Thomson, K; Richardson, D \& Gabriel, I (2000). Investigation of the effect of marathon running on leucocyte counts of subjects of different ethnic origins: relevamce to the aetiology of ethnic neutropenia. British Journal of Haematology 108(3):483-487.

2. Baj, Z; Kantorski, J; Majewska, E; Zeman, K; Pokoca, L; Fornalczyk, E; Tchorzewski, H; Sulowska, Z \& Lewicki, R (1994). Immunological status of competitive cyclists before and after the training season. International Journal of Sports Medicine 15(6):319-324.

3. Baum, M; Klopping-Menke, K; Muller-Steinhardt, M; Liesen, H \& Kirchner, H (1999). Increased concentrations of interleukin 1-beta in whole blood cultures supernatants after 12 weeks of moderate endurance exercise. European Journal of Applied Physiology 79(6):500-503.

4. Couzin, J (2004). Basic and clinical immunology meeting. An old favorite is resurrected: regulatory $\mathrm{T}$ cells take the stage. Science 305(5685):772.

5. Cowley, SC; Hamilton, E; Frelinger, JA; Su, J; Forman, J \& Elkins, KL (2005). CD4-CD8- T cells control intracellular bacterial infections both in vitro and in vivo. The Journal of Experimental Medicine 202(2):309-319.

6. D'Souza, CD; Cooper, AM; Frank, AA; Mazzaccaro, RJ; Bloom, BR \& Orme, IM (1997). An anti-inflammatory role for gamma delta $\mathrm{T}$ lymphocytes in acquired immunity to Mycobacterium tuberculosis. The Journal of Immunology 159 (3):1217-1221.

7. Durnin, JVG \& Womersley, J (1974). Body fat assessed from total body density and its estimation from skinfold thickness. British Journal of Nutrition 32:77-97.

8. Espersen, GT; Elbaek, A; Ernst, E; Toft, E; Kaalund, S; Jersild, C \& Grunnet, N (1990). Effect of physical exercise on cytokines and lymphocyte subpopulations in human peripheral blood. Acta Pathologica, Microbiologica et Immunologica Scandinavica 98:395-400.

9. Fu, SC; Qin, L; Leung, CK; Chan, BP \& Chan, KM (2003). Regular moderate exercise training prevents decrease of CD4+ T-lymphocytes induced by a single bout of strenuous exercise in mice. Canadian Journal of Applied Physiology 28(3):370-381.

10. Gabriel, H \& Kindermann, W (1991). Normal values of lymphocyte subpopulations in athletes. International Journal of Sports Medicine 12 (Abstract) 106.

11. Gabriel, H; Schmitt, B; Urhausen, A \& Kindermann, W (1993). Increased CD45RA + CD45RO+ cells indicate activated $\mathrm{T}$ cells after endurance exercise. Medicine and Science in Sports and Exercise 25(12):1352-1357.

12. Gabriel, H; Schwarz, L; Born, P \& Kindermann, W (1992). Differential mobilization of leucocyte and lymphocyte subpopulations into the circulation during endurance exercise. European Journal of Applied Physiology 65:529-534.

13. Gabriel, H; Urhausen, A \& Kindermann, W (1991). Circulating leucocyte and lymphocyte subpopulations before and after intensive endurance exercise to exhaustion. European Journal of Applied Physiology 63(6):449-457.

14. Gabriel, H; Urhausen, A; Brechtel, L; Muller, HJ \& Kindermann, W (1994). Alterations of regular and mature monocytes are distinct, and dependent of intensity and duration of exercise. European Journal of Applied Physiology 69(2):179-181.

15. Gmunder, FK; Lorenzi, G; Bechler, B; Joller, P; Muller, J; Ziegler, WH \& Cogoli, A (1988). Effect of long-term 
physical exercise on lymphocyte reactivity: similarity to spaceflight reactions. Aviation, Space, and Environmental Medicine 59:146-151.

16. Green, RL; Kaplan, SS; Rabin, BS; Stanitski, CL \& Zdziarski, U (1981). Immune function in marathon runners. Annals of Allergy 47:73-75.

17. Grose, RH; Thompson, FM \& Cummins, AG (2005). Deficiency of NK and CD1d-restricted V $\alpha 24+$ NK T-cells in Crohn's disease and ulcerative colitis. $3^{\text {rd }}$ Annual BMRP Investigator Meeting - Abstract.

18. Horn, PL; Leeman, K; Pyne, DB \& Gore, CJ (2002). Expression of CD94 and 56 (bright) on natural killer lymphocytes - the influence of exercise. International Journal of Sports Medicine 23(8):595-599.

19. Joffre, O; Gorsse, N; Romagnoli, P; Hudrisier, D \& van Meerwijk, JP (2004). Induction of antigen-specific tolerance to bone marrow allografts with CD4+CD25+ T lymphocytes. Blood 103(11):4216-4221.

20. Kajiura, JS; MacDougall, JD; Ernst, PB \& Younlai, EV (1995). Immune response to changes in training intensity and volume in runners. Medicine and Science in Sports and Exercise 27(8):1111-1117.

21. Kapazi, ZF; Ouslander, JG; Schnelle, JF; Kutner, M \& Fahey JL (2003). Effects of an exercise intervention on immunologic parameters in frail elderly nursing home residents. The Journals of Gerontology - Biological Sciences and Medical Sciences 58(7):636-643.

22. Kayashima, S; Ohno, H; Fujioka, T; Taniguchi, N \& Nagata, N (1995). Leucocytosis as marker of organ damage induced by chronic strenuous physical exercise. European Journal of Applied Physiology 70:413-420.

23. Keast, D; Cameron, K \& Morton, AR (1988). Exercise and the immune response. Sports Medicine 5:248-267.

24. Ladel, CH; Blum, C; Dreher, A; Reifenberg, K \& Kaufmann, SH (1995). Protective role of gamma/delta T cells and alpha/beta T cells in tuberculosis. European Journal of Immunology 25(10):2877-2881.

25. LaPerriere, A; Antoni, MH; Ironson, G; Perry, A; McCabe, P; Klimas, N; Helder, L; Schneiderman, N \& Fletcher, MA (1994). Effects of aerobic exercise training on lymphocyte subpopulations. International Journal of Sports Medicine Suppl 3: S127-S130.

26. Lewicki, R; Tchorzewski H; Majewska, E; Nowak, Z \& Baj, $Z$ (1988). Effect of maximal physical exercise on Tlymphocyte subpopulations and on interleukin 1 (IL 1) and interleukin 2 (IL 2) production in vitro. International Journal of Sports Medicine 9:114-117.

27. Mackinnon, LT (1992). Exercise and Immunology: Present and Future Directions. In Exercise and Immunology. Human Kinetics Publishers. Current Issues in Exercise Science Series, 85 .

28. MacNeil, B; Hoffman-Goetz, L; Kendall, A; Houston, M \& Arumugam, Y (1991). Lymphocyte proliferation responses after exercise in men: fitness, intensity, and duration effects. Journal of Applied Physiology 70(1):179-185.

29. McKune, AJ; Smith, LL; Semple, SJ \& Wadee, AA (2005). Influence of ultra-endurance exercise on immunoglobulin isotypes and subclasses. British Journal of Sports Medicine 39(9):665-670.

30. Mertens, DJ; Rhind, S; Berkhoff, F; Dugmore, D; Shek, PN \& Shephard, RJ (1996). Nutritional, immunologic and psychological responses to a $7250 \mathrm{~km}$ run. Journal of Sports Medicine and Physical Fitness 36(2):132-138.
31. Nieman, DC (1994). Exercise, Infection and Immunity. International Journal of Sports Medicine Suppl. 15:S131-S141.

32. Nieman, DC; Berk, LS; Simpson-Westerberg, M; Arabatzis, K; Younberg, S; Tan, AS; Lee, JW \& Eby, WC (1989). Effects of long-endurance running on immune system parameters and lymphocyte function in experienced marathoners. International Journal of Sports Medicine 10:317-323.

33. Nieman, DC; Buckley, KS; Henson, DA; Warren, BJ; Suttles, J; Ahle, JC; Simandle, S; Fagoaga, OR \& NehlsenCannarella, SL (1995). Immune function in marathon runners versus sedentary controls. Medicine and Science in Sports and Exercise 27(7):986-992.

34. Nieman, DC; Nehlsen-Cannarella, SL; Henson, DA; Koch, AJ; Butterworth, DE; Fagoaga, OR \& Utter, A (1998). Immune response to exercise training and/or energy restriction in obese women. Medicine and Science in Sports and Exercise 30(5): 679-686.

35. Pedersen, BK (1991). Influence of physical activity on the cellular immune system: mechanisms of action. International Journal of Sports Medicine Suppl.12:S23-S29.

36. Piccirillo, CA \& Shevach, EM (2004). Naturally-occurring CD4+CD25+ immunoregulatory T cells: central players in the arena of peripheral tolerance. Seminars in Immunology 16(2):81-88.

37. Pizza, FX; Mitchell, JB; Davis, BH; Starling, RD; Holtz, RW \& Bigelow, N (1995). Exercise-induced muscle damage: effect on circulating leukocyte and lymphocyte subsets. Medicine and Science in Sports and Exercise 27(3):363-370.

38. Rebelo, AN; Candeias, JR; Fraga, MM; Duarte, JA; Soares, JM; Magalhães, C \& Torrinha, JA (1998). The impact of soccer training on the immune system. Are the professional soccer players immune after an intensive training season? Journal of Sports Medicine and Physical Fitness 38(3):258-261.

39. Roberts, C; Pyne, DB \& Horn, PL (2004). CD94 expression and natural killer cell activity after acute exercise. Journal of Science and Medicine in Sport 7(2):237-247.

40. Rodrigues dos Santos, JA (2004). As alterações imunológicas induzidas por cargas repetidas de exercício muito prolongado podem ser indiciadoras de imunodepressão? Um estudo de caso. Revista Ludens 17 (4):27-33.

41. Rodrigues dos Santos, JA (2004). Alterações agudas induzidas por uma corrida de $50-\mathrm{km}$ em alguns parâmetros hematológicos, bioquímicos e urinários em sujeitos com diferentes níveis de treino. Revista Portuguesa de Medicina Desportiva 22:11-22.

42. Roitt, I; Brostoff, J \& Male, D (1989). Immunology. London: Gower Medical.

43. Scharhag, J; Meyer, T; Gabriel, HH; Schlick, B; Faude, O \& Kindermann, W (2005). Does prolonged cycling of moderate intensity affect immune cell function? British Journal of Sports Medicine 39(3):171-177.

44. Shek, PN; Sabiston, BH; Buguet A \& Radomski, MW (1995). Strenuous exercise and immunological changes: a multiple-time-point analysis of leukocyte subsets, CD4/CD8 ratio, immunoglobulin production and NK cell response. International Journal of Sports Medicine 16:466-474.

45. Shinkai, S; Shore, S; Shek, PN \& Shephard, RJ (1992). Acute exercise and immune function. Relationship between lymphocyte activity and changes in subset counts. International Journal of Sports Medicine 13(6):452-461.

46. Shore, S; Shinkai, S; Rhind, S \& Shephard, RJ (1999). Immune responses to training: how critical is training volume? Journal of Sports Medicine and Physical Fitness 39(1):1-11. 
47. Siri, WE (1961). Body composition from fluid spaces and density: Analysis of methods. In Brozek J, Henschel A (eds.) Techniques for Measuring Body Composition. National Academy of Sciences, National Research Council, Washington DC, 223-244.

48. Unal, M; Erdem, S \& Deniz, G (2005). The effects of chronic aerobic and anaerobic exercises in lymphocyte subgroups. Acta Physiologica Hungarica 92(2):163-171.

49. Woods, JA; Ceddia, MA; Zack, MD; Lowder, TW \& LU, Q (2003). Exercise training increases the naïve to memory T cell ratio in old mice. Brain, Behavior and Immunity 17(5):384-392.

50. Woods, JA; Davis, JM; Smith, JA \& Nieman, DC (1999). Exercise and cellular innate immune function. Medicine and Science in Sports and Exercise 31(1):57-66. 